\title{
Redefining Assessment in Tourism and Hospitality Education
}

\author{
Margie N. Roma ${ }^{1}$ \\ ${ }^{1}$ Jose Rizal University, Mandaluyong City, Philippines \\ Correspondence: Margie N. Roma, Jose Rizal University, Mandaluyong City, Philippines.
}

Received: April 14, 2020

Accepted: February 13, 2021

Online Published: February 19, 2021

doi:10.5430/ijhe.v10n4p113

URL: https://doi.org/10.5430/ijhe.v10n4p113

\begin{abstract}
Higher educational institutions (HEIs) play a substantial role in the development of knowledge and skills that can cope with the demands of industries in the fourth industrial revolution (4IR). This study examined the alignment between the current assessment practices used by HEIs and the competencies demanded by the hospitality and tourism industry. It also aimed to develop an assessment strategy typology that could specifically target the competencies required by the industry. In addition, the study was able to determine the three most and the three least preferred assessment methods as perceived by the hotel and restaurant management students in a private university in Mandaluyong City, Philippines. The findings revealed the common assessment methods employed by teachers in Hospitality and Tourism Management (HTM) major courses. The study argues that the use of these identified assessment methods likewise contributes to developing the emerging skills in the 4IR such as sense-making, social intelligence, novel and adaptive thinking, and new media literacy. Further, the innovative strategies in the application of the assessment methods were found to be effective in student learning. Accordingly, hospitality educators are encouraged to continuously hone their knowledge and skills to provide quality education and produce competent graduates ready to face the challenges of today's technological era.
\end{abstract}

Keywords: educational assessment, assessment methods, skills in the fourth industrial revolution

\section{Introduction}

The emergence of different sophisticated technologies in the tourism and hospitality industry, specifically the adoption of robots, artificial intelligence and service automation, is basically a response to the fourth industrial revolution (4IR) where several benefits, such as labour cost savings, value creation for customers, and image of an innovative high-tech company, are now enjoyed by the industry (Ivanov \& Webster, 2017). With these complex developments, higher educational institutions (HEIs) offering tourism and hospitality programs need to align their program, students, and course outcomes or goals to match the demands of this 4IR which, according to Benešová \& Tupa (2017), significantly affect production, labor market, and education.

The tourism industry, being an intensive work-market based on services, should address the continuous need for increasing the level of education by the formation of professional aptitudes and personnel quality in the present educational curriculums and courses to achieve excellence in the tourism field. In addition, synchronization between academia and industry also holds a unique position because the pass-out professionals, in the majority of the cases, will enter the industry to face real time situations (Manhas \& Dogra, 2011).

Necessarily, appropriate assessment of the learning strategies must be designed to confirm what students know, determine whether they have met curriculum outcomes or goals of their individualized programs, or to certify proficiency and make decisions about students' future programs or placements (Buendicho, 2013, p.1). Vlachou (2015) pointed out that the principles on assessment for learning are a part of learning and pedagogy, and that the processes involved can improve teaching and promote student learning, giving opportunities and skills to learners to become responsible for their own learning. In addition, Aziz, Akhter \& Habib (2016) underscored the importance of assessing student learning arguing that assessment is an essential part of a rational instructive experience and a vital part of an institutional push to enhance the nature of instruction and learning at all levels of education. Clearly, the underlying purpose of assessment and evaluation is to support and enhance the student learning experiences.

Several studies on teaching strategies focusing on effective student learning serve to challenge the 4IR in the higher education, particularly in the alignment of the knowledge and skills needed to cope with the demands of the tourism and hospitality industry. It is noted that higher education in the fourth industrial revolution (HE 4.0) is a complex, dialectical and exciting opportunity which can potentially transform society for the better. In this regard, the higher 
educational system in the Philippines needs to consider significant changes in the learning environment, including all forms of learning approaches that are found to be beneficial in producing the necessary skills in the 4IR.

On the other hand, Chao (2017), blamed the country's slow adaption to technological advances as a social infrastructure problem affecting both work and social life. Despite the various discussions about student-centered learning, learning outcomes, lifelong learning and even the use of ICT in education, the higher education still utilizes antiquated learning methods and the curriculums and programmed course barely catch up with the needs of the industry and contemporary social life. Further, Deale, O'Halloran, Jacques, \& Garger (2013) noted that little is known about what hospitality and tourism educators are doing in their classes and the types of teaching methods and resources they use.

Recognizing the significance of effective assessment methods in the development of the needed competencies in the 4IR industry, the researcher believes that a study should be made with the following objectives: 1) To examine the alignment between the assessment practices on hospitality students and the graduate competencies demanded by the industry in the fourth industrial revolution; and 2) To develop an assessment strategy typology that could specifically target the competencies demanded by the industry.

The results of the study will provide valuable insights to curriculum planning and academic decisions. In addition, the tourism and hospitality educators will have significant information about the most effective and preferred assessment methods that may be included as part of the teaching and learning activities. To the students, the research study will offer important information on the effectiveness of the learning assessments applied to them in class for their development and preparedness in the industry, especially the 4IR. For future researchers, the study will serve as a valuable reference that could provide relevant data on the effectiveness of the different assessment methods in developing the knowledge and skills of the students to meet the demands of the industry.

\section{Review of Related Literature}

\subsection{The Emerging Skills in the Fourth Industrial Revolution}

To underscore the significance of emerging skills in the 4IR, Schwab (2018) disclosed in the Global Competitiveness Report, that the skills as pillars of competitiveness captures the general level of skills of the workforce and the quantity and quality of education. While the concept of educational quality is constantly evolving, important quality factors today include developing digital literacy, interpersonal skills, and the ability to think critically and creatively. Anito and Morales (2019) proposed to reengineer the higher education curriculum to suit the emerging competency requirements of the labor market. Education embeds skills and competencies in the labor force. Highly-educated populations are more productive because they possess greater collective ability to perform tasks and transfer knowledge quickly while creating new knowledge and applications.

Clearly, the industry expects a lot from HEIs in producing competent individuals ready to join the workforce. HEIs need to take a serious look on these emerging skills for them to be able to assess if they can still provide the present requirements of the 4IR. Educators, being the most important entity in the skills development of the students, need also to be aware and properly equipped with the fast-changing technological environment. As cited in the study of Bakhru (2018), teachers can incorporate the competencies into their course and delivery to improve their effectiveness in the classroom, elevate their student knowledge, and make them better prepared and equipped for the business world (Bakhru et al., 2013).

Examining the alignment between the educational assessment methods and the competencies demanded by the tourism and hospitality industry under the 4IR, this study looked into the emerging skills described in various literature. These skills include sense-making, social intelligence, novel and adaptive thinking, cross-cultural competency, computational thinking, new media literacy, transdisciplinarity, design mindset, cognitive load management, and virtual collaboration (Davies, Fidler, \& Gorbis, 2011). These skills are alternatively termed as critical thinking, people management skills, cognitive flexibility, and knowledge production and management (Xing \& Marwala, 2017).

The distinct characteristics of the emerging skills established in various literature provided clear and valuable insights in the teaching-learning process that includes the effective application of the different assessment methods. Students can acquire the necessary competencies if teachers have a deep understanding on how assessments can develop such emerging skills. The skills acquired and developed by the students while in college are very important as they could determine their competencies and competitiveness in the tourism and hospitality industry under the 4IR.

Indeed, educational institutions play a vital role in providing the students with the skills necessary to respond to the 
fast-changing work environment. In the same vein, the educational system should also be dynamic to produce skills that are adaptive and aligned with the demands of the industry. In particular, tourism and hospitality education needs to focus on building tomorrow's manpower to provide the hospitality industry with high-quality human resources, the industry, the academia, and the government who must collaboratively work towards the enhancement and strengthening of the tourism and hospitality education (Chand, 2016).

\subsection{Learning Assessment Models}

On perspective of educational assessment, it is very important that teachers are thoroughly aware of the processes in determining how successful they are in student learning (Garcia, 2008). Cited in the book of Garcia (2008) is the concept of assessment, which refers to the full range of information gathered and synthesized by teachers about their students and their classrooms (Arends, 1994). This information can be gathered in both informal and formal ways such as observation, assignments, tests, written reports, and other outputs. It actually looks into how much change has occurred on the student's acquisition of a skill, knowledge or value before and after a given learning experience (Garcia, 2008).

Garcia (2008) identified in his said book the purposes of educational assessment as: improvement of student learning, identification of students' strengths and weaknesses, assessment of the effectiveness of a particular teaching strategy, appraisal of the effectiveness of the curriculum, assessment and improvement of teaching effectiveness, and communication with and involvement of parents in their children's learning. It is necessary for educators to really learn and deeply understand the objectives of assessment.

The Philippine Commission on Higher Education (CHED) recommends several assessment strategies for the hospitality and tourism management programs (CHED CMO 62, 2017). This includes work projects, written and oral questions, reports, demonstrations and simulations, problem solving, portfolio, journals, interviews, projects, and role plays. These assessment methods serve as guide on how educators can assess the knowledge and skills of their students in the teaching-learning process. Teachers in the College of Tourism and Hospitality Management in the subject university of this study are encouraged to use these methods but the application and level of effectiveness of such methods in terms of appropriateness to every subject should be a constant discussion to develop the skills required by the tourism and hospitality industry in the 4IR. As indicated in the same CHED CMO, the policies, standards, and guidelines for Bachelor of Science in Tourism Management (BSTM) and Bachelor of Science in Hospitality Management (BSHM) should be followed by the higher educational institutions offering the said programs.

As the main purpose of this study is to examine the alignment between the assessment practices on hospitality students and the graduate competencies demanded by the industry in the fourth industrial revolution, this paper intends to fill the gap in the literature investigating the effectiveness and usefulness of the current assessment methods being utilized by HTM faculty to the students in the development of knowledge and skills required by the tourism and hospitality industry under the 4IR.

Relevant data were gathered from hospitality students, particularly the most commonly-used assessment methods in their major courses, and their most and least preferred assessment tools. The collected information was useful in the course syllabi review and in the teaching methodology and assessment. Teachers may be able to identify the most appropriate assessment approach for their lessons, but the students may have different capacities and preferences, which should also be addressed accordingly. The diversity of the student's population in the tourism learning world at present needs to be considered and continuously studied.

\section{Method}

The descriptive method of research employing the mixed methods approach was used in looking into the alignment of the different assessment methods applied in class with the demands of the tourism and hospitality industry under the 4IR in terms of knowledge and skills development. A researcher-made survey questionnaire was prepared and validated by the Research Committee of the institution to gather the needed data, particularly those pertaining to the student learning assessments, including the most preferred and considered useful as well as the least preferred and considered least useful. Identifying the frequency and ranking of the assessment methods provided significant analysis that supported the objectives of this study.

The participants to the study were the third year HRM students in a private University in Metro Manila, Philippines. The survey questionnaire was to be administered to 116 Hotel and Restaurant Management students as the study's population frame but managed to have only 89 participants or at 77 percent retrieval rate. The instrument inquires about the commonly-used assessment methods in class, as well as the most and the least preferred learning 
assessment methods of the students. The problems encountered by the students in the facilitation of the assessments were also asked for inclusion in the results and recommendations of the study.

In addition, various data relative to the continuous improvement on the teaching and learning process being implemented in the HTM department, as well as observation and personal experience were also utilized to provide better perspective on the result of this study.

\section{Findings}

Inquiring on the commonly-used assessment methods in class, data showed that quizzes topped the list. Major examinations (Prelim, Midterm, and Final Examinations), group work, assignments also fill the list. Interestingly, attendance is also reported as an assessment method. It is worth mentioning that quizzes, major exams, and assignments are mandatory requirements for college faculty to give to their students as inputs to the computer-based Academic Information Management System (AIMS) for the computation of the student grades in a given grading period.

Quizzes and major exams are tests usually given by teachers through paper-and-pencil procedure to measure students acquisition of knowledge (Garcia, 2008). However, Moore (1992) pointed out that tests cannot measure student motivation, physical limitations, and even environmental factors. As observed in many years of teaching, majority of the hospitality students are not comfortable with written examinations. Most of the time, only few students get a very good grade on these methods of assessment, while those who failed have different reasons such as lack of time to finish the test, unclear instructions, not able to study, and many more. Teachers are then forced to make interventions even if they believe that passing the quiz and major exam are deemed necessary in assessing the learning of the students. The reduction on the percentage component given to exams as part of student grade was partly due to these instances.

At present, since educational institutions are adapting with technological changes, exams can already be taken in an online platform outside the traditional classroom environment which again as observed is much preferred by the students. Further, teachers now are more creative in converting the traditional paper-and-pencil procedure into physical task or activity which they believe are being enjoyed by the students apart from developing the needed skills in the 4IR such as novel and adaptive thinking, which refers to analytical and innovative thinking, creativity, originality, initiative, and ability to solve complex problems (World Economic Forum, 2018), as well as social intelligence. Written answers compel students to compose their own unique answers to demonstrate their understanding. Skills are being developed when students try to articulate their thinking and to argue on a certain point.

However, in today's technological era, written exams are still part of the assessment methods given by the industry to job seekers. Although there are numerous types of exams, still, students need to be prepared and learn to accept that written exam is one way of assessing learning.

On the other hand, group work or activity is a collaborative task among group or groups of students which can be viewed as an effective method in developing social intelligence. In the study of Davies, et al. (2011), social intelligence is the ability to connect to others in a deep and direct way, to sense and stimulate reactions and desired interactions. Some teachers also give activities in group that can develop novel and adaptive thinking skills and new media literacy, which is the ability to critically assess and develop content that uses new media forms, and to leverage these media for persuasive communication (Davies, et al., 2018). It can be observed that most students enjoy working in a group though some problems still exist such as lack of cooperation on some members to finish a particular task and even lack of time to accomplish the task.

Surprisingly, teachers still assess students based on attendance. It was a practice before that attendance has a corresponding small percentage component in the students' grade. This is to encourage students to always come on class and have the opportunity to perform. Though attendance at present has been disregarded as part of students' grade, encouraging the students to attend the class is quite challenging for teachers. Constant reminders are given to students that class activities constitute a big percentage of their grade; thus, their absence might affect their grade.

Giving assignment or homework is common to teachers. Homework is defined as academic tasks assigned by teachers to be done by students outside of the instructional time (Bembenutty \& White, 2012; Cooper, Steenbergen-Hu, \& Dent, 2012). Assignment can be helpful like for example, advance reading of lessons to prepare students for the next meeting discussion or quiz. But for some students, assignment can be stressful specially if it requires more time to accomplish like data gathering or any research activity. Depending on the level of difficulty, it can still be viewed as an effective method in developing skills specially if the assignment requires collaborations, 
research work, analytical and critical thinking.

Recitations, educational tours, and projects were also recorded in this study as assessment methods. Class recitation is usually done to assess the extent of student's knowledge in a particular topic. However, since done individually, fear is obvious with the students and this should not be the case as recitation should develop self-confidence. This method can also be considered as an active role played by the student in the learning process, thus can develop their personality and communication skills. Educational or familiarization tour is also very useful and effective learning method in hospitality courses. Assessment methods can be observation checklist, documentation, reflection paper, oral presentation, and others that will validate student learning through the said experiential activity. This method can develop interpersonal skills, analytical and critical thinking. The usual concerns encountered in familiarization tour are the appropriateness of the activities and high price thus, tour providers and the academe must make a joint effort in providing students the best experience in learning and skills development at a reasonable price. On the other hand, class project has always been a tangible thing thus, most of students perceived this as additional cost in their learning. It can be done individually or in group. It maybe pertinent to note that there are hospitality courses that require project as part of the grading component. The projects can be a research output, a new recipe, a development plan, facility layout, planning and implementation of event, and many others, which believed to be effective in skills development. Upon examining the aforementioned skills of the future, accomplishing certain project or output can develop sense making or attention to detail (World Economic Forum, 2018), social intelligence or the ability to connect to others in a deep and direct way, to sense and stimulate reactions and desired interactions (Davies, et al., 2011), as well as, novel and adaptive thinking or analytical and innovative thinking, creativity, originality, initiative and the ability to solve complex problems (World Economic Forum, 2018).

Laboratory work and seatwork were also identified as assessment methods and can also be viewed as commonly-used by teachers. With laboratory work, hospitality program includes skills-based courses that will enhance the competencies of the students in the field of housekeeping, food and beverage, cookery, bar management, and others. Institutions offering this program should have the facilities to properly equipped students with the competencies required. As observed, majority of the hospitality students enjoy laboratory activities with actual demonstration as evidence of their learning. Apparently, some skills that can be developed from this method are sense making, social intelligence, and novel and adaptive thinking. However, some important issues raised by the students that need to be addressed are improvement of the facilities and lack of time to finish laboratory task. On the other hand, seatwork, defined as pupils working alone on an assigned task, is a common activity in classrooms but our knowledge about what teachers actually do during this activity is limited (Svanes \& Klette, 2018). Some teachers in the college level employ variety of strategies, like an assigned task can be accomplished by a group instead of individual student or a sort of giving incentive or prize to those who will accomplish the task first. This is to make this method somehow enjoyable and fun because some students find this uninteresting. However, some students prefer to do seatwork because they find this effective for their learning while others find this as an escape for class discussions. It is again a challenge for teachers to incorporate activities in seatwork that will develop the skills of the future.

Research activity is very common to all hospitality courses. Some students prefer this, others are not. As educator, developing research skill among the students will help them to be more competitive in the industry. However, with its time-consuming nature, specially if the activity entails a lot of data gathering, many students do not prefer this activity. Many teachers encounter difficulty in using this method, especially on the quality of the data students present. It may also be important to note that research activity also includes reading and writing skills, which some students find it very demanding. With its somehow negative insight from the students, it is still necessary to incorporate research activities to all hospitality courses. While the challenge is on the educators, developing the skills of the students is still the main consideration. On the other hand, attendance to seminar or workshop definitely enhances student learning. The main reason of doing this is for the students to have a better perspective on matters related to tourism and hospitality and for them to be exposed on the trends and issues in the industry. This activity can enhance their social intelligence, as well as their novel and adaptive thinking. However, not all students are capable of doing this due to financial issues.

Registering the least scores among the list of assessments are oral reporting, events management, and role playing. Oral reporting has always been an issue to college students, particularly when asked to report on their lesson, which for them is the job of their teacher. This maybe the reason why some teachers are hesitant to use this method. The researcher witnessed the change on this aspect. Currently, teachers just ask for the students to report on examples or come up with video presentations and even share in the class actual experiences which they can relate with the concepts and principles of the lesson. In this case, the approach is more actual and real which teachers can easily 
assess student learning. This method can develop student's communication skills, creativity, innovative thinking and new media literacy. On the other hand, events management is not commonly-used by teachers as the hospitality program includes events management course. However, there are some courses that students still need to plan and execute events as some teachers need to assess their management skills and other competencies such as in their catering and culinary class. This method can develop their social intelligence, as well as novel and adaptive thinking. Lastly on role playing, the researcher feels that some teachers do not explore yet the benefits of this method in student learning. In the study of Kilgour, Reynaud, Northcote, and Shields (2015), role-play is one type of active and participatory learning activity that creates interaction between students and a simulated scenario. This reality can serve to open the minds of participants to issues they need to be able to deal with in their chosen careers. However, it is observable that students with introvert personality do not enjoy such activity. This method maybe challenging to both teachers and students, but this can develop interpersonal skills as students empathize more with the given situation and build rapport with each other. Role play further develops skills like soft skills, teamwork and also enables students to apply theory into practice (Bakhru, 2018).

With this discussion, it can be noted the important role played by educational institutions, most especially educators in the development of skills necessary in the 4IR. Finding innovative ways of engaging college students in learning that will truly impact their future practice in their chosen career is a challenging task for the teacher. Once discovered however, these methods can bring great satisfaction to both students and teachers (Kilgour, et al., 2015). Further, teachers are expected to have sufficient knowledge and ability so that they can choose the method or model of learning that is conducive and in accordance with students' learning ability and able to involve students' activeness in the learning process (Wibobo, Friana, \& Pelipa, 2018). In consideration to the skills of the future, it can be a challenge for educators but they are also expected to continually hone their competencies so they can produce competent individuals ready to face the demands of the tourism and hospitality industry in the 4IR.

Moreover, it would be interesting to find out which among these commonly-used methods are the most preferred and the least preferred by the student-respondents which they find most useful and least useful to their career. Table 1 presents the frequency distribution of the three most preferred and considered most useful assessment methods chosen by the respondents.

Table 1. Most preferred assessment methods

\begin{tabular}{lrr}
\hline & Frequency & Rank \\
\hline Recitation & 22 & 5 \\
Quiz & 21 & 6 \\
Project & 7 & 10 \\
Major exam & 37 & 2 \\
Group work & 13 & 8 \\
Seatwork & 4 & 12 \\
Educational tour & 26 & 3 \\
Laboratory work & 55 & 1 \\
Oral reporting & 17 & 7 \\
Attendance to seminar/workshop & 17 & 7 \\
Research work & 9 & 9 \\
Role playing & 5 & 11 \\
Events management & 13 & 8 \\
Assignment & 4 & 12 \\
Class attendance & 23 & 4 \\
\hline
\end{tabular}

Table 1 shows that the three most preferred and considered most useful by the respondents were laboratory work, at Rank 1; major exam, at Rank 2; and educational tour, at Rank 3. This implies that students greatly benefit from 
laboratory work, which involved actual learning experience while working on a particular activity or task. It is noted that as part of the requirements of their course, HRM students are given skills training on basic culinary and basic food preparation, front office procedures, and bar management, among others. Further, this corroborates the finding in a study by Lashley (1999), that hospitality and tourism management students displayed enjoyment in practical activity, rather than theorizing and reflection. This also relates to the study of Stevens et al. (2012), which confirms previous research suggesting that hospitality students learn best "by doing." The assessment method such as actual demonstration during laboratory period can enhance the competencies of the students as well as develop situational adaptability (Davies, et al., 2011). Teachers handling laboratory subjects are also expected to be competent on their field and to constantly improve their knowledge and skills in line with todays' technological era.

On the other hand, major examination, which ranked second in the three most preferred and useful assessment method, is a compulsory requirement in the computation of the student grades and is also a major factor in determining the student's academic performance. Obviously, the students are aware that major exam is a mandatory requirement and a major factor in their overall grade for a particular course, which they have to pass. However, as stated earlier, some teachers at present are converting the traditional paper-and-pencil approach into a more actual or hands-on approach which is effective for hospitality students and can develop skills such as social intelligence and novel and adaptive thinking. But whatever approach to be used, teachers should know that the main objective of their assessment should correspond in developing student knowledge and competencies.

The third most useful measure is educational tour, which provides off-campus experiential learning experience to the students. Goh (2011) pointed out that there is a need for institutions to include fieldtrips as part of their course curriculum given the known benefits and students' perception of enhancement of understanding on course materials. This is important in hospitality and tourism education due to the practical nature of the need to have hands-on experience. One recommendation given was to ensure that year 1 and senior students should have two different fieldtrip experience outcomes. This tends to support the students' selection of the educational tour as their third choice of most preferred learning assessment. This activity as mentioned, can develop interpersonal skills, analytical and critical thinking, which are useful with their performance in the industry. Thus, it can be said that the three most preferred and considered most useful measures all contributed to student learning and can develop necessary skills to cope with the demands of the 4IR.

Table 2. Least preferred assessment methods

\begin{tabular}{lrr}
\hline & Frequency & Rank \\
\hline Recitation & 9 & 10 \\
Quiz & 12 & 9 \\
Project & 28 & 4 \\
Major exam & 4 & 14 \\
Group work & 17 & 7 \\
Seatwork & 21 & 6 \\
Educational tour & 4 & 14 \\
Laboratory work & 5 & 13 \\
Oral reporting & 30 & 2 \\
Attendance to seminar/workshop & 15 & 8 \\
Research work & 23 & 5 \\
Role playing & 56 & 1 \\
Events management & 7 & 3 \\
Assignment & 29 & 11 \\
Class attendance & 8 & 12 \\
\hline
\end{tabular}

Table 2 shows the result in investigating the students' least preferred and considered least useful assessment methods. 
This study found that role playing, oral reporting, and assignments topped the list. Apparently, role playing as the number one of the three least preferred measures but included as a commonly-used assessment methods, is not yet appreciated by the students as an effective method used in hospitality courses even as existing literature on the matter suggests its use as a tool to facilitate learning. In the study of Kilgour, et al., (2015), it was found that the use of role-play as a learning strategy in higher education has been used in problem-based learning and online contexts and is also considered to be a useful strategy in teacher education. The said paper concluded, among others, that role-play learning activities have the capacity to address emotional as well as cognitive dimensions of adult learning, and that good quality learning and teaching in the tertiary sector needs to include environment that ignites inquiry and motivation. As mentioned in this study earlier, this method can develop social intelligence, but apparently, the students do not prefer this method because it involves memorization and some familiarity with the character or role they will play. It is also somehow a time-consuming classroom activity. Despite these issues with the students, teachers need to also explore the benefits of this method and can come up with some strategies that hospitality students will appreciate.

In the case of oral reporting, which ranked second as the least preferred assessment method, it can be surmised that students were not "comfortable" with speaking and presenting their assigned topic before the class either for lack of self-confidence or lack of verbal communication skill. Shyness could also a factor which the student can not overcome. Also, as mentioned, this became an issue with the students particularly when asked to report on their lesson, which for them is the job of their teacher. However, with the current strategies of some teachers to make oral reporting a more engaging activity, it has been observed that students are active and participative especially when they present personal experiences related to the concepts and principles of the lesson. With this, it can be said that it is an effective method of assessing student learning and definitely can develop self-confidence, student's communication skills, creativity, innovative thinking and new media literacy.

The third least preferred measure, assignment, is understandably one activity that is apparently disliked, especially by lazy students, as it entails researching, reading, and writing, which all consume considerable time and effort. Admittedly, however, that giving assignment to students is a common teaching practice, in probably all learning disciplines. And again, depending on the level of difficulty, it can still be viewed as an effective method in developing skills specially if the assignment requires collaborations, research work, analytical and critical thinking.

On the problems encountered in the facilitation of the different assessment methods, Table 3 contains the different problems identified by students, together with their individual ranking.

Table 3. Problems encountered in the facilitation of assessment methods

\begin{tabular}{lrr}
\hline & Frequency & Rank \\
\hline Lack of books/reference materials & 32 & 5 \\
No equipment (i.e., laptop for presentation) and other materials & 25 & 8 \\
Lack of time to finish the task/activity & 56 & 1 \\
Lack of laboratory tools and equipment & 44 & 4 \\
Classroom/laboratory facilities need improvement & 29 & 6 \\
Lack of coordination/cooperation among groupmates & 53 & 2 \\
Financial issues & 46 & 3 \\
Professor's instructions are not clear (e.g., major exam, activities) & 26 & 7 \\
Inappropriate teaching strategy/approach & 22 & 9 \\
\hline
\end{tabular}

As may be gleaned from Table 3, there were nine problems encountered by the students, with lack of time to finish the task or activity at Rank 1, which obtained a total of 56 responses; followed by lack of coordination/cooperation among group mates with 53 responses at Rank 2, and financial issues with 46 responses at Rank 3. Coming in close was lack of laboratory tools and equipment with 44 responses at Rank 4 . The other five problems obtained less than forty responses at Rank 5 to 9 . Taking a serious look at these problems, it may be said that solutions to these problems are all "doable" and can be resolved either by the management of the University or by HRM faculty. For example, Rank 1 problem which states the lack of time to finish the task/activity is mainly a judgment call on the concerned faculty, except for laboratory work, such as food preparation and bar management, which require extra 
time for completion. A review on the policy on this aspect will be in order and appropriate planning and time management should come into play for this particular problem. On the other hand, Rank 2 problem which involved the lack of coordination and cooperation among group mates may also be solved by the concerned faculty by simply giving constant reminders to the class or groups to always practice coordination and cooperation whenever group work/activity is assigned, especially during laboratory work or working on a project. Financial issues, which rank third, refer to financial requirement for project and laboratory-related needs (example, cooking ingredients) can be discussed by the faculty with the students. Worthy to mention is the problem of inappropriate teaching strategy/approach, which is ranked 9 or with fewest responses. This means that being the least of the problems encountered by the students, the inappropriateness of the teaching strategy had somewhat been addressed with the implementation of the university's continuing faculty development program.

\section{Conclusions and Recommendations}

On the basis of the findings of the study, it was found out that the common assessment methods applied in major hospitality courses are: recitation, quiz, project, major exam, group work, seatwork, educational tour, laboratory work, oral reporting, attendance to seminar or workshop, research work, role playing, events management, assignment, and class attendance. Consequently, the use of the said assessment methods still develops the skills required by the industry in the 4IR, such as sense-making, social intelligence, novel and adaptive thinking, and new media literacy. Further, it was found out that the three most preferred and most useful methods for the respondents are laboratory work, major exam, and educational tour, which are all mandatory to hospitality courses. Both laboratory work and educational tour exhibit active learning, while changing the traditional paper-and-pencil procedure to a more actual or hands-on approach in major exam is already being practiced in some of the courses, which teachers believe to be the most effective way of assessing their students. On the other hand, the three least preferred and least useful methods are role playing, oral reporting, and assignment, all of these require much time and effort that students apparently dislike. However, as traditional and time-tested assessment methods, they should be used by means of innovative approaches, including the application of modern technology. It can be noted that these methods also develop necessary skills to prepare students in the industry. Likewise, hospitality educators are expected to continuously hone their knowledge and skills to provide quality education and produce competent graduates ready to face the challenges of today's technological era.

The study also implies the formulation of policies (by CHED) that will provide guidance to higher educational institutions to be dynamic and proactive to anticipate sudden changes in educational environment with particular stress on the teaching-learning strategies. This will ensure the continued development of knowledge and skills appropriate in the fourth industrial revolution.

Most of the problems identified by the respondents can be given appropriate action either by the management or by the HRM faculty concerned. The following recommendations were formulated and submitted for appropriate disposition:

1. HRM Faculty to continue applying the three identified most useful assessment methods, while introducing innovative teaching techniques on the three least preferred methods - oral reporting, role playing, and assignment - to make them interesting to the students. It is noted that these methods are long tested learning tools that could enhance student learning. In addition, instructions given to students should be repeated and ensure that the same are properly acknowledged.

2. HRM Faculty to assign class activities, projects, and other course-related requirements that are within the financial capacity of the students.

3. University Management to consider the procurement of additional tools and equipment, and at the same time further improve laboratory facilities that will augment to the development of skills ready to the challenges of the fourth industrial revolution.

4. CHTM to consider the extension of time during laboratory work. Similarly, HRM Faculty to assign class activities or projects that can be completed on the allotted time.

This study was conducted at only one college program in a private university in Mandaluyong, Philippines which is the Hospitality and Tourism Management Program. The results of this study cannot be made as basis for generalization. This means that further research initiatives should be made to support the findings of this study, particularly on the effectiveness of the current assessment methods in preparing the students in the 4IR in other field of studies and whether the three most preferred assessment methods - laboratory work, major exam, and educational tour - identified by the hospitality students as useful to them will be the same learning assessment methods to be 
chosen by students in other disciplines. In addition, large sample covering different course programs may provide new knowledge from future research.

\section{References}

Anito, J., \& Morales M. (2019). The Pedagogical Model of Philippine STEAM Education: Drawing Implications for the Reengineering of Philippine STEAM Learning Ecosystem. Universal Journal of Educational Research, 7(12), 2662-2669. https://doi.org/10.13189/ujer.2019.071213

Arends, R. I. (1994). Learning to Teach (3e). New York: Mc Graw-Hill, Inc.

Aziz, F., Akhter, M., \& Habib, Z. (2016). Diverse Assessments of Female Students' Performance and their Perceptions about Assessment Tools. Bulletin of Education and Research, 38(1), 117-132.

Bakhru, K. M., Sanghi, S., \& Medury, Y. (2013). A principal component analysis of teaching competencies required for management education. Arth Prabhand: A Journal of Economics and Management, 2(7), 1-15.

Bakhru, K. M. (2018). Aligning teaching methods for learning outcomes: a need for educational change in management education using quality function deployment approach. Int. J. Learning and Change, 10(1), 54-69. https://doi.org/10.1504/IJLC.2018.10008662

Benešová, A., \& Tupa, J. (2017). Requirements for education and qualification of people in industry 4.0. International Conference on Flexible Automation and Intelligent Manufacturing. Procedia Manufacturing, 11(1), 2195-2202. https://doi.org/10.1016/j.promfg.2017.07.366

Buendicho, F. (2013). Assessment of Learning 1. Manila: Rex Book Store, Inc.

Bughin, J., Hazan, E., Lund, S., Dahlstrom, P., Wiesinger, A., \& Subramaniam, A. (2018). Skill shift automation and the future of the workforce. Brussels: McKinsey Global Institute.

Chand, M. (2016). Building and Educating Tomorrow's Manpower for Tourism and Hospitality Industry. International Journal of Hospitality \& Tourism Systems, 9(1), 53-57.

Chen, R., Subhash, K., George, V., \& Weiemair, K. (2012). Learning Motivation, Performance, and Satisfaction: A Comparison between Students Majoring in Tourism and Hospitality Programmes from Taiwan and India. International Journal of Hospitality \& Tourism Systems, 5(1), 1-11.

Corpuz, B., \& Salandanan, G. (2015). Principles of Teaching. QC: Lorimar Pub., Inc.

Davies, A., Fidler, D., \& Gorbis, M. (2011). Future Work Skills 2020. CA: Institute for the Future for the University of Phoenix Research Institute.

Deale, C., Halloran, R., Jacques, P., \& Garger, J. (2013). An Examination of Current Hospitality and Tourism Teaching Methods. Journal of Hospitality and Tourism Education, 22(1), 20-29. https://doi.org/10.1080/10963758.2010.10696973

Garcia, C. (2008). Measuring and Evaluating Learning Outcomes: A Textbook in Assessment of Learning 1 \& 2. Mandaluyong City: Books Atbp. Publishing Corp.

Green, A. J., \& Sammons, G. E. (2014). Student Learning Styles: Assessing Active Learning in the Hospitality Learners Model. Journal of Hospitality \& Tourism Education, 26(1) 29-38. https://doi.org/10.1080/10963758.2014.880617

Goh, E. (2011). The Value and Benefits of Fieldtrips in Tourism and Hospitality Education. Higher Learning Research Communications, 1(1), 60-70. https://doi.org/10.18870/hlrc.v1i1.18

Ivanov, Stanislav Hristov and Webster, Craig, Adoption of Robots, Artificial Intelligence and Service Automation by Travel, Tourism and Hospitality Companies - A Cost-Benefit Analysis (2017). Prepared for the International Scientific Conference "Contemporary Tourism - Traditions and Innovations", Sofia University, 19-21 October 2017. Available at SSRN: https://ssrn.com/abstract=3007577

Kilgour, P., Reynoud, D., Northcote, M., \& Shields, M. (2015). Role-Playing as a Tool to Faciitate Learning, Self-Refection and Social Awareness in Teacher Education. International Journal of Innovative Interdisciplinary Research, 2(14), 8-20.

Kim, A., \& Davies, J. (2013). A Teacher's Perspective on Student Centred Learning: Towards the Development of Best Practice in an Undergraduate Tourism Course. Journal of Hospitality, Leisure, Sport \& Tourism Education, 14(1), 6-14. https://doi.org/10.1016/j.jhlste.2013.12.001 
La Lopa, J. (2013). The Difference Between Bigfoot \& Learning Styles: There May Be Better Evidence to Support the Existence of Bigfoot. Journal of Hospitality, Leisure, Sport \& Tourism Education. https://doi.org/10.1080/15428052.2013.817861

Manhas, P. S., \& Dogra, J. (2011). Hospitality and Tourism Management Graduates Expectations: Future Implications for the Educators. Journal of Tourism, 7(1).

Maric, M., Penger, S., Todorovic, I., Djurica, N., \& Pintar, R. (2015). Differences in Learning Styles: A Comparison of Slovenian Universities. Procedia - Social and Behavioral Sciences, 197(1), 175-183. https://doi.org/10.1016/j.sbspro.2015.07.079

Mega, C., Ronconi, L., \& De Beni, R. (2014). What Makes a Good Student? How Emotions, Self-Regulated Learning, and Motivation Contribute to Academic Achievement. Journal of Educational Psychology, 106(1), 121-131. https://doi.org/10.1037/a0033546

Mushtaq, I., \& Khan, S. N. (2012). Factors Affecting Students' Academic Performance. Global Journal of Management and Business Research, 12(9), 17-22.

Rynne, J., Kwek, A., \& Bui, J. (2012). Insights into the Academic Motivation of Tourism and Hospitality Students in a Research Methods Course. Journal of Hospitality \& Tourism Education, 24(2), 28-39. https://doi.org/10.1080/10963758.2012.10696667

Schwab, K. (2018). The Global Competitiveness Report 2018. Geneva, Switzerland: World Economic Forum.

Stevens, D. P., Kitterlin, M., \& Tanner, J. R. (2012). Assessing the Impact of Learning Styles for Hospitality Students. Consortium Journal of Hospitality \& Tourism, 17(1), 1-23.

Svanes, I. K., \& Klette. K. (2018). Teachers' instructional practices during pupils' individual seatwork in Norwegian language arts. Education Inquiry, 9(3), 247-266. https://doi.org/10.1080/20004508.2017.1380485

World Economic Forum. (2018). The future of jobs report 2018. Geneva, Switzerland: World Economic Forum Centre for the New Economy and Society.

Xing, B., \& Marwala, T. (2017). Implications of the fourth industrial age on higher education. https://doi.org/10.25073/0866-773X/87

York, T., Gibson, C., \& Rankin, S. (2015). Defining and Measuring Academic Success. Practical Assessment, Research and Evaluation, 20(15), 1-20. https://doi.org/10.7275/hz5x-tx03

\section{Copyrights}

Copyright for this article is retained by the author(s), with first publication rights granted to the journal.

This is an open-access article distributed under the terms and conditions of the Creative Commons Attribution license (http://creativecommons.org/licenses/by/4.0/). 